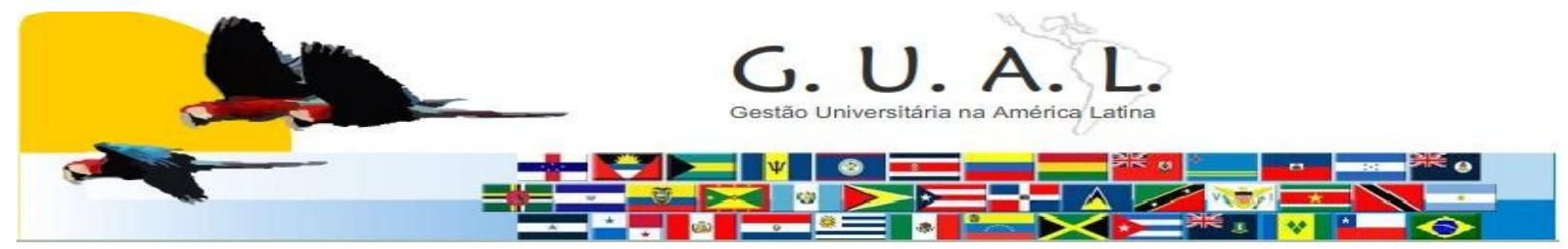

ISSN 1983-4535

\title{
ANÁLISE DA RELAÇÃO DO IGC COM O NÍVEL DE INTEGRAÇÃO VIRTUAL NAS IES DE MELHOR DESEMPENHO NO BRASIL
}

\section{ANALYSIS OF THE RELATIONSHIP WITH THE IGC VIRTUAL INTEGRATION LEVEL OF PERFORMANCE IN BRAZIL IES}

Bruno César Linhares da Costa Silva, Graduando Universidade Federal do Rio Grande do Norte - UFRN brunoclcs@yahoo.com.br

Isadora Rebeca Andrade de Souza, Graduanda Universidade Federal do Rio Grande do Norte - UFRN isadorarebeca@hotmail.com

Natália Veloso Caldas de Vasconcelos, Mestre Universidade Federal do Rio Grande do Norte - UFRN nataliaveloso@hotmail.com

Jamerson Viegas Queiroz, Doutor Universidade Federal do Rio Grande do Norte - UFRN jvqjamerson@yahoo.com.br

Fernanda Cristina Queiroz, Doutor Universidade Federal do Rio Grande do Norte - UFRN fernandacbpereira@yahoo.com.br

Dalliane Vanessa Pires Andrade, Bacharel Universidade Federal do Rio Grande do Norte - UFRN

Recebido em 25/outubro/2011 dallianevanessa@yahoo.com.br

Aprovado em 13/janeiro/2012

Sistema de Avaliação: Double Blind Review

Esta obra está sob uma Licença Creative Commons Atribuição-Uso. 


\title{
RESUMO
}

O Sistema de Ensino Superior se constitui sob uma base multidimensional para atendimento de diversas necessidades de transformação dos diversos atores da sociedade. No Brasil, o SINAES - Sistema Nacional de Avaliação Ensino Superior - busca essa perspectiva e, para isso, utiliza, além de outros índices e métodos de avaliação, do IGC - Índice Geral de Cursos - o qual resume em um único indicador, para cada universidade, os resultados particulares dos cursos de graduação, mestrado e doutorado. Nesse sentido, definiu-se como objetivo deste estudo verificar a relação do Índice Geral de Cursos (IGC) com o nível de integração virtual com os egressos das universidades que conseguiram os melhores índices (entre 4 e 5). Assim, fez-se uso de uma abordagem metodológica do tipo qualitativa com objetivos de caráter exploratório através de pesquisas bibliográfica e documental. Por fim, conclui-se que a existência de uma página eletrônica que mantem um vinculo com o egresso não influencia no Índice Geral de Curso.

Palavras-chave: Ensino superior. Qualidade. Avaliação. Egressos.

\begin{abstract}
The Higher Education System is constituted based on a multidimensional treatment of various changing needs of the different actors of society. In Brazil, the Sinai - the National Assessment of Higher Education - search this perspective and, therefore, uses, and other indices and methods of evaluation, the IGC - General Index of Courses - which boils down to a single indicator for each university, the particular outcomes of undergraduate, master's and doctoral degrees. In this sense, we defined the objective of this study verify the relationship of the General Course (IGC) with the level of integration with the virtual university graduates who have achieved the best rates (between 4 and 5).Thus, it was a use of a qualitative methodological approach for the purposes of exploratory research through literature and public documents. Finally, we conclude that the existence of a web page that maintain a link with the convicted does not influence the course of the General Index.
\end{abstract}

Keywords: Higher education. Quality. Evaluation. Graduates. 


\section{INTRODUÇÃO}

O Sistema de Ensino Superior se constitui sob uma base multidimensional para atendimento de diversas necessidades de transformação dos diversos atores da sociedade. Considerar o ex-aluno, egresso de um curso de formação superior, no processo de avaliação institucional é um dos caminhos que se têm proposto para mensurar e promover ações no sentido de atender satisfatoriamente a diversidade de interesses sob os quais as universidades caminha.

No Brasil, o SINAES - Sistema Nacional de Avaliação Ensino Superior - apresenta, em seus princípios e objetivos, a necessidade de ter-se essa perspectiva de avaliação integrada a fim de construir um atendimento às demandas sociais. Esse sistema utiliza-se de diversos índices e métodos para a consecução da avaliação do desempenho das universidades. O IGC, Índice Geral de Cursos, é um deles e resume em um único indicador, para cada universidade, os resultados particulares dos cursos de graduação, mestrado e doutorado.

Nesse sentido, o presente artigo pretende pesquisar o seguinte problema: Existe uma relação entre a existência de integração virtual com egressos e a consecução de bons Índices Geral de Cursos (IGC) pelas universidades?

Para isso, definiu-se como objetivo geral verificar a relação do Índice Geral de Cursos (IGC) com o nível de integração virtual com os egressos das universidades que conseguiram os melhores índices. Especificamente, pretende-se (i) pesquisar as universidades com os melhores IGC (entre 4 e 5), (ii) pesquisar, entre essas universidades, quais possuem integração virtual com o egresso, (iii) analisar comparativamente o IGC e a integração virtual as instituições de ensino superior (IES) pesquisadas.

Este estudo está organizado em 6 sessões. A primeira sessão que é esta, refere-se a esta introdução, apresentando o tema e definindo os objetivos, além do problema de pesquisa. A sessão 2 apresenta-se a metodologia desta pesquisa; na sessão 3, faz-se revisão bibliográfica a cerca da importância do egresso na avaliação de uma IES; na sessão 4, desenvolve-se o estudo de caso desta pesquisa; na sessão 5, discorre-se as considerações finais; e finalmente, na sessão 6, estão elencados as referências bibliográficas utilizadas para a consecução deste estudo. 


\section{MÉTODO DE PESQUISA}

A pesquisa realizada teve uma abordagem do tipo qualitativa. A classificação da pesquisa, levando em consideração os objetivos, tem caráter exploratório. Quanto ao planejamento da pesquisa optou-se pela pesquisa bibliográfica, e em seguida foi desenvolvido um estudo de caso.

Para a realização do estudo, foram listadas todas as instituições de ensino superior brasileiras com Índice Geral de Cursos (IGC) iguais a quatro e a cinco. Após essa listagem, foi feita uma pesquisa com o uso da internet para saber quais dessas instituições tinham em seus sites eletrônicos um espaço relacionado aos egressos. O acesso foi feito através do site da instituições e em seguida, foi-se pesquisando dentro do site da instituição, se no mesmo tinha algum link, imagem ou notícia que se informa algo sobre os egressos.

Para tabulação dos dados, foi utilizada uma tabela, visando o preenchimento da mesma, e ao final da pesquisa, as conclusão seriam feitas, com base nesses dados coletados e preenchido na planilha. Segue abaixo, a tabela 1, que representa o modelo de planilha utilizada para coletar os dados da pesquisa.

TABELA 1 Modelo para coleta de dados

\begin{tabular}{|c|c|c|c|c|c|c|c|c|c|c|c|}
\hline $\begin{array}{l}\text { IE } \\
\text { S }\end{array}$ & Sigla & $\begin{array}{c}\text { UF } \\
\text { (Sede } \\
\text { ) }\end{array}$ & $\begin{array}{l}\text { Município } \\
\text { (Sede) }\end{array}$ & $\begin{array}{c}\text { Organização } \\
\text { Acadêmica }\end{array}$ & $\begin{array}{l}\text { IG } \\
\text { C }\end{array}$ & $\begin{array}{c}\text { Dependência } \\
\text { Administrativa }\end{array}$ & $\begin{array}{c}\text { Existe } \\
\text { site para } \\
\text { egressos? }\end{array}$ & $\begin{array}{l}\text { Quais } \\
\text { campos }\end{array}$ & $\begin{array}{c}\text { É } \\
\text { atualizado? }\end{array}$ & $\begin{array}{c}\text { O } \\
\text { egresso } \\
\text { pode } \\
\text { inserir } \\
\text { dados }\end{array}$ & $\begin{array}{c}\text { Breve } \\
\text { descrição } \\
\text { do site }\end{array}$ \\
\hline
\end{tabular}

Fonte: Elaboração Própria, 2011

Ao total foram pesquisados 70 sites de instituições, nas quais, 46 IES obtiveram IGC igual a 4 e 24 obtiveram IGC igual a 5 . As IES que fizeram parte desta pesquisa seguem no ANEXO I essas informações, bem como suas notas do índice geral de curso.

A divisão das IES analisadas pode ser feita por região, neste caso, consideramos a tabela 2, para verificação.

Pode-se notar a superioridade das IES, localizadas na região Sul do Brasil, visto que na análise, elas representam 54,2\% das instituições analisadas. A região preocupante na qual apresenta apenas uma instituição que foi analisada foi à região Norte. 
TABELA 2 Analise das IES por região

$\begin{array}{ccc}\text { Região } & \text { Estado } & \text { Número de IES analisadas } \\ \text { Centro-Oeste } & \text { DF } & 1 \\ \text { Centro-Oeste } & \text { GO } & 1 \\ \text { Centro-Oeste } & \text { MS } & 2 \\ \text { Nordeste } & \text { BA } & 1 \\ \text { Nordeste } & \text { CE } & 1 \\ \text { Nordeste } & \text { PB } & 2 \\ \text { Nordeste } & \text { PE } & 3 \\ \text { Nordeste } & \text { RN } & 1 \\ \text { Norte } & \text { AM } & 1 \\ \text { Sudeste } & \text { ES } & 2 \\ \text { Sudeste } & \text { MG } & 13 \\ \text { Sudeste } & \text { RJ } & 11 \\ \text { Sudeste } & \text { SP } & 12 \\ \text { Sul } & \text { PR } & 6 \\ \text { Sul } & \text { RS } & 11 \\ \text { Sul } & \text { SC } & 2\end{array}$

Fonte: Elaboração Própria, 2011

$\mathrm{Na}$ seção seguinte, serão apresentados alguns conceitos sobre relacionando a importância do egresso para a avaliação de um curso se graduação.

\section{A IMPORTÂNCIA DO EGRESSO PARA A AVALIAÇÃO DE UM CURSO DE GRADUAÇÃO}

Conforme Cerqueira-Adão (2011) as organizações, de um modo geral, estão percebendo através de constantes avaliações a necessidade de agir de modo diferente para sobreviverem no mundo atual.

Segundo Rodrigues (2011) o sistema de ensino superior no Brasil é bastante complexo, regulado por leis, decretos, portarias, emendas constitucionais e medidas provisórias que embasam e sustentam o funcionamento das instituições.

Sistema de Ensino Superior se constitui sob um complexo conjunto de processos educacionais que se voltam a atender a diversas expectativas dos vários setores da sociedade. O que o governo, o setor acadêmico, a sociedade e os setores produtivos demandam das Instituições de Ensino Superior (IES) podem ser distintos entre si. Assim, o sentido de qualidade da educação superior deve caminhar para o consenso satisfatório entre todas essas questões, buscando adaptar-se a essa perspectiva da multidimensionalidade através de 


\section{ANÁLISE DA RELAÇÃO DO IGC COM O NÍVEL DE INTEGRAÇÃO VIRTUAL NAS IES DE MELHOR DESEMPENHO NO BRASIL}

avaliações que sejam propostas para a integração dos diversos atores desse processo. (ABREU JUNIOR, 2009).

A questão da qualidade emerge como questão central, em razão das expectativas que gravitam em torno do papel contemporâneo da educação superior e do valor social assumido pelo conhecimento decorrente das transformações no mundo do trabalho. Questionam-se os modelos de financiamento da universidade pelo Estado e a imposição da crescente racionalização dos processos acadêmicos. A avaliação institucional surge, pois, como um dos pilares da gestão universitária racionalizada. (ABREU JUNIOR, 2009, p.258)

Sobral (2009) coloca que a qualidade de uma IES se configura como complexa por ter como desafio contemporâneo de atender aos anseios de três dimensões, não excludentes: a dimensão acadêmica, a dimensão econômica e a dimensão social. A primeira delas caracterizada pela produção do conhecimento, a segunda pela demanda pela inovação tecnológica e parcerias com o setor produtivo, e a terceira, pela relevância social da pesquisa e do desenvolvimento de tecnologias sociais. "Especificamente, a avaliação deve ser baseada na qualidade e excelência dos resultados, na especificidade das áreas de conhecimento e no impacto dos resultados na comunidade acadêmica e empresarial e na sociedade" (SOBRAL, 2009, p. 233).

Cada IES deve analisar e escolher o sistema avaliativo que melhor se adéqua ás suas características e expectativas e a partir disso promover a reavaliação de suas práticas sempre com o olhar de compreensão das repercussões quanto à promoção e socialização do saber para a apreensão e modificação da realidade. Enfim, o processo avaliativo é sempre uma prática voltada para uma ação modificadora. (LOUSADA; MARTINS, 2005).

Segundo o INEP - Instituto Nacional de Estudos e Pesquisas Educacionais Anísio Teixeira, o Sistema Nacional de Avaliação do Ensino Superior (SINAES), institucionalizado no Brasil, é formado pela avaliação das instituições, dos cursos e do desempenho dos estudantes. Dessa forma, conforme (POLIDORI, 2009), o SINAES tem como objetivo de melhorar a qualidade do ensino superior no país a partir da manutenção de um processo de avaliação de instituições, cursos e alunos. Para isso são realizados processos de avaliação in loco da instituição e dos cursos, acrescido da auto avaliação da universidade, além da realização do Exame Nacional de Desempenho dos Estudantes.

Ainda, o SINAES surge com a proposta de respeitar as diversidades das instituições de ensino, quanto à história, identidade e missão (POLIDORI, 2009). Entretanto, toda a atual avaliação se vale de dados de caráter apenas internos, deixando de levar em consideração as 


\section{ANÁLISE DA RELAÇÃO DO IGC COM O NÍVEL DE INTEGRAÇÃO VIRTUAL NAS IES DE MELHOR DESEMPENHO NO BRASIL}

repercussões externas que a instituição produz, inclusive se estão alinhadas aos seus objetivos. Trazer a importância disso em muito iria contribuir para a eficácia desses exames, por englobar as visões e demandas de setores externos.

Para garantir o atendimento às demandas desses setores, é necessário também visualizar as Instituições de Ensino Superior sob a ótica de uma organização que presta serviços e, logicamente, observar o seu processo com as devidas entradas, mão de obra, meios de trabalho, saídas e, principalmente, para quem esses processos se destinam, os clientes, os quais expressam satisfação ou não. (CORDEIRO; MOTTA, 2008). Isso porque, dessa maneira, é possível delimitar todos os fatores de interação e a partir disso identificar falhas e promover as melhorias necessárias. Além disso, ao invés de isoladamente fazer análises comparativas de entradas e saídas e/ou dos elementos que constituem o processo de transformação (de formação), agrega-se a visão do cliente, tornando o diagnóstico ainda mais preciso, por o cliente ser o usuário do resultado.

Neste escopo de sistemas de avaliação, um aspecto interessante é que realidade das Universidades Comunitárias Gaúchas - UCGs é um pouco diferente, o Consórcio das Universidades Comunitárias (COMUNG) possuía um programa específico de avaliação, o PAIUNG, que foi criado em 1994, baseado no Programa de Avaliação Institucional das Universidades Brasileiras (PAIUB), que foi criado em 1993.

Então, sendo a universidade uma instituição de ensino que presta serviços à sociedade, esta é sua cliente. (CORDEIRO; MOTTA, 2008). A sociedade caracterizada pelo egresso do curso de ensino superior - que irá utilizar do valor agregado à sua formação para se colocar no mercado - e pelo mercado de trabalho - que absorverá esses egressos.

O egresso de um curso de graduação é o cliente e também o resultado do processo de formação do ensino universitário. Os alunos são clientes por participarem do processo educacional como um todo, é ele que está sendo transformado, é também, nesse sentido, a entrada do processo. (BROCHADO; PITHON; PEREIRA, 2008). Além disso, é também cliente porque espera como resultado uma posição no mercado, advindo de sua qualificação. Já o mercado de trabalho, apesar de mero desfrutador do produto de todo o processo de formação profissional, ele compartilha reciprocamente com o egresso por ambos terem suas necessidades atendidas.

Assim sendo, a sociedade é o principal elemento dentro do sistema de educação, é ela que ora está sendo transformada ora está usufruindo do produto transformado. Logo, deve ser considerada para avaliar se o processo de educação atende as necessidades dela: de formação 


\section{ANÁLISE DA RELAÇÃO DO IGC COM O NÍVEL DE INTEGRAÇÃO VIRTUAL NAS IES DE MELHOR DESEMPENHO NO BRASIL}

e de ter mão de obra qualificada. (BROCHADO; PITHON; PEREIRA, 2008). O egresso tem um grande papel por já ser um cliente na sociedade e, mais que isso, ser um indicador da satisfação das necessidades do mercado à medida que ele é absorvido por sua área de formação.

Nessa lógica, as Instituições de Ensino Superior (IES) devem ter o compromisso com o oferecimento de seus serviços com qualidade para a sociedade assim como qualquer outra organização deve estar assim também comprometida com a qualidade do produto ou serviço que oferece aos seus clientes e exigida por eles. (CORDEIRO; MOTTA, 2008). Perseguindo continuamente a qualidade sob este ponto de vista, a universidade está em busca de atingir seus objetivos e proporcionar o atendimento de critérios que seus clientes consideram importantes.

O porquê da busca dessa qualidade? Segundo Costa (2007 apud CORDEIRO; MOTTA, 2008, p.3):

[...] a qualidade [...] consiste na 'plena satisfação do cliente'. Isso significa que a qualidade na prestação de serviços é essencial ao perfeito funcionamento de qualquer empresa. Também é, tudo que alguém faz ao longo de um processo para garantir a fidelidade do consumidor, obtendo exatamente aquilo que desejar, em termos de características intrínsecas, custos, atendimento e resultados. Ou seja, o cliente é o eixo central dos projetos de qualidade.

É de extrema relevância identificar os fatores que são de importância para os clientes e compará-los com o desempenho que a organização está executando para que seja possível tomar as decisões adequadas que permitam aproximar esses critérios do cliente à performance da organização. Em uma universidade, para se alcançar isso, há a necessidade de se considerar a visão do egresso na avaliação da qualidade do ensino. Por isso, é importante identificá-los como clientes e determinar suas necessidades para o desenvolvimento da qualidade do ensino sob uma ótica de melhoria e adaptação contínua. (CORDEIRO, MOTTA, 2008; BROCHADO, PITHON, PEREIRA, 2008). Desse modo, conforme Cordeiro e Motta (2008, p. 4), "os discentes como principais clientes do serviço prestado pela instituição, podem ser a referência para atestar essa qualidade e por consequência contribuir para a continuidade desse serviço".

Para Lousada e Martins (2005), a inserção do quesito "egresso" no processo avaliativo institucional da universidade irá contribuir com a análise qualitativa da instituição conferindo à avaliação um estado de respeitabilidade, desempenho, qualidade e prestígio externo. 


\section{ANÁLISE DA RELAÇÃO DO IGC COM O NÍVEL DE INTEGRAÇÃO VIRTUAL NAS IES DE MELHOR DESEMPENHO NO BRASIL}

Entretanto, essa inserção não deve ocorrer apenas com confecção de pesquisas isoladas, e, sim, desenvolvendo uma ferramenta comunicativa que promova o acompanhamento sistemático desses egressos por pelo menos um período de tempo predeterminado para que se possibilite a análise da evolução da trajetória profissional.

Espartel (2009) propõe que a avaliação de um curso de ensino superior pelo egresso deve ocorrer sob as dimensões direta e indireta. A primeira diz respeito ao exame de elementos como currículo, professores, bibliotecas, entre outros. Já a segunda, leva em consideração uma perspectiva de longo prazo, analisando, a partir do egresso, o impacto do curso no seu desempenho profissional. Combinando essas avaliações, é possível identificar melhorias a serem implementadas e desenvolver meios de relacionamento com o formado.

Segundo esse mesmo autor, o formado é de interessante importância nesse sentido de avaliação de um curso de graduação, pois pode tornar-se indicador de desempenho quando em uma visão de ferramenta de controle e que possibilita identificar ações de melhorias promovendo a gestão do ensino superior.

No caminho da implementação de um sistema avaliativo que contemple a visão dos egressos aparecerão algumas barreiras as quais devem ocorrer devido a falta de tradição com esse tipo de estudo. A dificuldade de localização dos egressos tem sido um problema generalizado, pois não há um costume de os formados encaminharem seus novos dados para a instituição de ensino (LOUSADA; MARTINS, 2005).

Com esse tipo de avaliação, segundo Costa e Ângelo de Deus (2008), é possível discernir com bastante clareza pontos fortes e fracos do curso e, por consequência, investir em novos procedimentos para aprimorar a formação que o curso de graduação está proporcionando.

Nesse sentido, não somente o curso passa a ter a clareza de quais diretrizes de melhorias tomar, mas, inclusive, os próprios graduandos, de posse das informações geradas pelas avaliações dos egressos, poderá direcionar sua preparação para o mercado de trabalho. Isso porque poderá visualizar as tendências, projetar cenários, definir objetivos e planejar ações de formação. (COSTA; ANGELO DE DEUS, 2008).

Brochado, Pithon e Pereira (2008) afirmam que os egressos como aqueles que buscam a absorção pelo mercado de trabalho, ou seja, desejam que seja necessidade da sociedade, são um ótimo indicador da relação de qualidade $\frac{\text { formação }}{\text { necessidade da sociedade }}$ e que, assim, pode contribuir na retroalimentação com informações ao sistema educacional de forma a 


\section{ANÁLISE DA RELAÇÃO DO IGC COM O NÍVEL DE INTEGRAÇÃO VIRTUAL NAS IES DE MELHOR DESEMPENHO NO BRASIL}

proporcionar melhorias desde o início do processo a fim de alinhar a formação educacional oferecida com as necessidades da sociedade demandadas.

Segundo Meira e Kurcgant (2009, p. 482):

O egresso enfrenta no seu cotidiano de trabalho situações complexas, que o levam a confrontar as competências desenvolvidas, durante o curso, com as requeridas no exercício profissional. Pode, a partir daí, avaliar a adequação da estrutura pedagógica do curso que foi vivenciado, bem como os aspectos intervenientes no processo de formação acadêmica.

Vale salientar que as pesquisas com os egressos tendem a ser diferentes daquelas realizadas com alunos no que se refere à seriedade, à maturidade e à fidelidade com a realidade. E isso repercute em proposições de melhorias também mais eficazes.

Outro motivo para desenvolver uma avaliação do ensino superior sob também a perspectiva do egresso é o fato de que, segundo Alves, Rossi e Vasconcelos (2003), as tendências e exigências profissionais estão em constante transformação e para se promover a qualidade e competitividade desses alunos no mercado de trabalho são válidas as adaptações de propostas pedagógicas a essas exigências e transformações.

É muito importante a universidade receber esse retorno da qualidade dos formandos que estão sendo oferecidos à sociedade quanto à aptidão à atividade profissional. Isso porque as mudanças drásticas que vêm ocorrendo no mundo do trabalho, da economia e da sociedade, como a globalização, os avanços tecnológicos, a crescente oferta de cursos superiores e as novas exigências de preparação dos profissionais, obriga as instituições de ensino superior a formarem profissionais cada vez mais multidisciplinares, capazes de exercerem diferentes funções, realizar diferentes atividades, resolver problemas com rapidez e segurança, além daqueles ligados à sua área de formação. (LOUSADA; MARTINS, 2005).

Mas, conforme Lousada e Martins (2005), não se trata de curvar a universidade às exigências do mercado, mas de desenvolver uma troca de informações em mão dupla que permita chegar a um padrão satisfatório de qualidade e exigência de profissionais. Alguns dados são muito significantes nesse processo: atividade profissional e cidadã com as devidas adaptações aos setores em que atuam, tempo de estabilização no mercado, competências, autonomia, perspectivas e continuação de atividades acadêmicas.

Nesse sentido, para Luiz, Costa A. e Costa H. (2009), verificar a transformação que ocorreu no aluno inserido na sociedade devido ao currículo agregado à sua formação profissional aliando ao sistema nacional de avaliação do ensino superior e verificar a 


\section{ANÁLISE DA RELAÇÃO DO IGC COM O NÍVEL DE INTEGRAÇÃO VIRTUAL NAS IES DE MELHOR DESEMPENHO NO BRASIL}

percepção do egresso a cerca do processo educacional é uma forma de promover o diálogo e interação entre as visões dos diversos atores. Uma avaliação deve estar baseada no objeto ao qual se dirige e somente será eficaz a depender dos valores e interesses dos envolvidos e, assim, haver a possibilidade de ocorrer uma avaliação que contemple a totalidade dos fatores determinantes para os problemas da educação universitária.

Assim, segundo Alves, Rossi e Vasconcelos (2003), inserir o egresso como mais um elemento de avaliação da educação superior não é apenas uma análise de produtividade e eficácia dos processos de um curso de graduação como tem sido as avaliações até então. É também a análise das contribuições do sistema de produção do ensino sobre a sociedade, ou seja, uma forma de analisar as influências sobre a sociedade. E mais que isso, a partir dessa análise, é também a promoção da cultura focada de cada vez mais proporcionar interferências positivas para a coletividade.

\section{ANÁLISE DOS DADOS}

O IGC se tornou um índice de relevância importância nas instituições. Tal índice auxilia coordenadores de cursos na tomada de decisões. Isso porque o IGC é um reflexo da qualidade da instituição, graças aos vários campos que ele avalia. Um desses campos avaliados é o egresso.

Cada instituição tem sua política de acompanhamento do egresso para que sua opinião seja recolhida da melhor maneira possível. Algumas delas optam pela criação de um espaço exclusivo para ex-alunos em suas páginas na internet. Nesse espaço, além de receber sugestões e críticas dos egressos, é disponibilizado recursos para que a instituição continue mantendo um vínculo com o aluno mesmo depois de ter concluído o curso.

Como a internet, hoje em dia é considerado o meio mais fácil para manter o contato com quem se distancia, acredita-se que as instituições que realmente levam em consideração a opinião do seu egresso na avaliação da instituição recolhem tais informações pelos sites. Assim, foi feita uma pesquisa nos sites das instituições para saber quais delas tem um espaço para os egressos em seu site. Após isso, será feita uma comparação para saber se as instituições com IGC igual a quatro utiliza menos os sites eletrônicos do que as com IGC igual a cinco para recolher e levar em consideração a opinião dos egressos.

Ao todo, foram analisadas setenta instituições de ensino superior. Dessas, quarenta e seis possuíam IGC igual a quatro, enquanto vinte e quatro possuíam IGC igual a cinco. Ao analisar os sites dessas instituições, observou-se que da totalidade das IES que tinham site, 
$58 \%$ das que tinham site, correspondiam as IES com IGC igual a quatro, enquanto nas que tinham IGC igual a cinco, o percentual correspondente foi de $42 \%$,

TABELA 3 Informações sobre IGC

\begin{tabular}{crrrr} 
& \multicolumn{3}{c}{ Tem site relacionado ao egresso? } \\
\cline { 2 - 5 } IGC & \multicolumn{2}{c}{ SIM } & \multicolumn{2}{c}{ NÃO } \\
4 & 15 & $58 \%$ & 31 & $70 \%$ \\
5 & 11 & $42 \%$ & 13 & $30 \%$ \\
\hline TOTAL & \multicolumn{2}{c}{26} & \multicolumn{3}{c}{44}
\end{tabular}

Fonte: Elaboração própria, 2011

Além disso, dos sites visitados, sete deles não estavam atualizados. No entanto, alguns dos sites só tinham suas informações disponíveis para os egressos cadastrados, sendo impossível analisar se as informações dispostas ali, sem saber se as mesmas eram atualizadas ou não.

\begin{tabular}{|c|c|c|c|}
\hline IES & IGC & $\begin{array}{l}\text { DEP. } \\
\text { ADM }\end{array}$ & DESCRIÇÃO DO SITE \\
\hline $\begin{array}{l}\text { Universidade Federal de } \\
\text { Itajubá - UNIFEI }\end{array}$ & 4 & Pública & $\begin{array}{l}\text { O cadastro no site tem quatro etapas. Com isso, acredito } \\
\text { que eles colham tantas informações pessoais como } \\
\text { profissionais. O site não tem notícias e é pobre em } \\
\text { informações. }\end{array}$ \\
\hline $\begin{array}{l}\text { Universidade Estadual de } \\
\text { Ponta Grossa }\end{array}$ & 4 & Pública & $\begin{array}{l}\text { O site é bastante completo. Permite que qualquer um } \\
\text { tenha acesso a dados, como e-mail e empresa que } \\
\text { trabalha, dos egressos. }\end{array}$ \\
\hline $\begin{array}{c}\text { Universidade Federal de } \\
\text { Santa Maria }\end{array}$ & 4 & Pública & $\begin{array}{l}\text { O site ainda se encontra em formação, apesar de ter sido } \\
\text { inaugurado em } 2002 \text {. O concurso de crônica é realizado } \\
\text { entre egressos que escrevem sobre algo que } \\
\text { vivenciaram na universidade. As melhores recebem } \\
\text { premiação, inclusive em dinheiro. }\end{array}$ \\
\hline $\begin{array}{l}\text { Universidade Federal do } \\
\text { Ceará }\end{array}$ & 4 & Pública & $\begin{array}{l}\text { O site tem pouquíssimas informações e, pelas notícias } \\
\text { cadastradas, percebe-se que ele não é atualizado. }\end{array}$ \\
\hline $\begin{array}{l}\text { Universidade Federal de } \\
\text { Santa Catarina }\end{array}$ & 4 & Pública & $\begin{array}{l}\text { O site é recente. Foi lançado em dezembro de } 2010 \text {. } \\
\text { Talvez seja por isso que não tenha informações mais } \\
\text { relevantes. Ou então, essas informações ficaram } \\
\text { exclusivas para egressos que fazem o cadastro. }\end{array}$ \\
\hline $\begin{array}{l}\text { Universidade Federal de } \\
\text { Alfenas }\end{array}$ & 4 & Pública & $\begin{array}{l}\text { O site é simples, porém, pela descrição do mesmo na } \\
\text { página inicial, ele aparenta ter mais informações } \\
\text { exclusivas para ex-alunos cadastrados. }\end{array}$ \\
\hline $\begin{array}{l}\text { Universidade } \\
\text { Tecnológica Federal do } \\
\text { Paraná }\end{array}$ & 4 & Pública & $\begin{array}{l}\text { Cada Campi tem seu site. Os sites são simples e alguns } \\
\text { só pedem para o egresso se cadastrar. O site do campus } \\
\text { de Campo Mourão é o mais completo. Nele também } \\
\text { tem um link de um blog para ex-alunos: http://ex- } \\
\text { alunoutfpr.blogspot.com/ }\end{array}$ \\
\hline
\end{tabular}




\begin{tabular}{|c|c|c|c|}
\hline $\begin{array}{l}\text { Instituto Militar de } \\
\text { Engenharia }\end{array}$ & 5 & Pública & $\begin{array}{l}\text { O site se caracteriza como um ponto de encontro de ex- } \\
\text { alunos. O ex-aluno se cadastra no site para ter seu nome } \\
\text { publicado na sua turma. Em alguns campos é preciso } \\
\text { fazer login pra ter acesso. }\end{array}$ \\
\hline $\begin{array}{l}\text { Faculdade de Economia } \\
\text { e Finanças IBMEC }\end{array}$ & 5 & Privada & $\begin{array}{l}\text { No site tem a informação de que a maioria dos itens tem } \\
\text { acesso exclusivo para ex-alunos e, para acessá-los, é } \\
\text { necessário efetuar o login. Isso dificulta ao acesso sobre } \\
\text { informações mais detalhadas de eventos para ex-alunos. }\end{array}$ \\
\hline $\begin{array}{l}\text { Faculdade de } \\
\text { Odontologia São } \\
\text { Leopoldo Mandic }\end{array}$ & 5 & Privada & $\begin{array}{l}\text { O site tem vários serviços para os ex-alunos, porém a } \\
\text { maioria só informa o número do telefone ou e-mail para } \\
\text { que o aluno possa ter maiores informações sobre o item } \\
\text { selecionado. Alguns itens, como "oportunidade de } \\
\text { trabalho", estão sem informação e inacessíveis. O site } \\
\text { disponibiliza o acesso ao questionário aplicado aos } \\
\text { egressos e os respectivos resultados. }\end{array}$ \\
\hline $\begin{array}{l}\text { Escola de Administração } \\
\text { de Empresas de São } \\
\text { Paulo }\end{array}$ & 5 & Privada & $\begin{array}{l}\text { O site possui um link para uma comunidade que reúne } \\
\text { alunos, ex-alunos e professores. O acesso é restrito a } \\
\text { esses. }\end{array}$ \\
\hline $\begin{array}{l}\text { Faculdade de Medicina } \\
\text { de São José do Rio Preto }\end{array}$ & 5 & Pública & $\begin{array}{l}\mathrm{O} \text { site tem o objetivo de cadastrar os egressos e } \\
\text { disponibilizar para eles um questionário avaliativo, no } \\
\text { entanto o site está em construção e sem acesso. }\end{array}$ \\
\hline $\begin{array}{c}\text { Fundação Universidade } \\
\text { do Estado de Santa } \\
\text { Catarina } \\
\end{array}$ & 4 & Pública & $\begin{array}{l}\text { O site possui apenas um espaço para o cadastro dos ex- } \\
\text { alunos. }\end{array}$ \\
\hline $\begin{array}{l}\text { Fundação Universidade } \\
\text { Federal de Ciências da } \\
\text { Saúde de Porto Alegre }\end{array}$ & 5 & Pública & $\begin{array}{l}\text { O site possui apenas um espaço para o cadastro dos ex- } \\
\text { alunos. }\end{array}$ \\
\hline $\begin{array}{l}\text { Fundação Universidade } \\
\text { Federal de Viçosa }\end{array}$ & 5 & Pública & $\begin{array}{l}\text { O site possui um link que dá acesso a um questionário } \\
\text { no formato Word. Deduziu-se assim, que os egressos } \\
\text { respondem o questionário e o encaminham para algum } \\
\text { e-mail. }\end{array}$ \\
\hline $\begin{array}{l}\text { Pontifícia Universidade } \\
\text { Católica de São Paulo }\end{array}$ & 4 & Privada & $\begin{array}{l}\text { O site possui um espaço onde os egressos podem se } \\
\text { cadastrar, trocar fotos, ter acesso a noticias e } \\
\text { informativos sobre eventos que interessam a aqueles. }\end{array}$ \\
\hline Universidade de Brasília & 4 & Pública & O site para os egressos se encontra fora do ar. \\
\hline $\begin{array}{l}\text { Universidade Estadual de } \\
\text { Londrina }\end{array}$ & 4 & Pública & $\begin{array}{l}\text { A universidade possui um portal para os egressos, mas } \\
\text { os dados se encontram desatualizados. Os dados } \\
\text { estatísticos, por exemplo, são do ano de } 2006 \text {. }\end{array}$ \\
\hline $\begin{array}{l}\text { Universidade Estadual } \\
\text { Paulista Júlio de } \\
\text { Mesquita Filho }\end{array}$ & 4 & Pública & $\begin{array}{l}\text { A universidade possui um espaço em seu site para o } \\
\text { cadastro dos ex-alunos. }\end{array}$ \\
\hline $\begin{array}{l}\text { Universidade Federal de } \\
\text { Lavras }\end{array}$ & 5 & Pública & O site disponibiliza os e-mails e telefones dos egressos. \\
\hline $\begin{array}{l}\text { Universidade Federal de } \\
\text { Minas Gerais }\end{array}$ & 5 & Pública & $\begin{array}{l}\text { A universidade possui uma página onde é possível o } \\
\text { cadastramento dos egressos. Além disso, informa a } \\
\text { participação desses no mercado de trabalho e possui } \\
\text { links úteis para tais. }\end{array}$ \\
\hline
\end{tabular}




\section{ANÁLISE DA RELAÇÃO DO IGC COM O NÍVEL DE INTEGRAÇÃO VIRTUAL NAS IES DE MELHOR DESEMPENHO NO BRASIL}

\begin{tabular}{c|c|c|l}
\hline $\begin{array}{c}\text { Universidade Federal de } \\
\text { São Carlos }\end{array}$ & 5 & Pública & $\begin{array}{l}\text { O site da universidade possui um espaço para o cadastro } \\
\text { dos egressos. }\end{array}$ \\
\hline $\begin{array}{c}\text { Universidade Federal de } \\
\text { São João Del Rei }\end{array}$ & 4 & Pública & $\begin{array}{l}\text { A página para os egressos da universidade possui links } \\
\text { de acesso a informações e serviços. }\end{array}$ \\
\hline $\begin{array}{c}\text { Universidade Federal de } \\
\text { Uberlândia }\end{array}$ & 4 & Pública & $\begin{array}{l}\text { O site possui um espaço para o egresso se cadastrar. } \\
\text { Após o cadastro, ele tem acesso a informações que são } \\
\text { exclusivas para os egressos. Ou seja. A comunidade } \\
\text { externa não tem acesso ao portal. }\end{array}$ \\
\hline $\begin{array}{c}\text { Universidade Federal do } \\
\text { Rio Grande do Sul }\end{array}$ & 5 & Pública & $\begin{array}{l}\text { O site da universidade possui um link para que os } \\
\text { egressos preencham um questionário online. }\end{array}$ \\
\hline $\begin{array}{c}\text { Universidade FEEVALE } \\
\text { a universidade possui um portal completo para a }\end{array}$ \\
\hline
\end{tabular}

QUADRO 1 Instituições x IGC x Dep. Adm x Descrição do site Fonte: Elaboração própria, 2011

Em sua maioria, os sites dispunham de atualizações de vagas de emprego, divulgação de eventos, divulgação de cursos de especialização e tinha como objetivo principal manter um vínculo entre a instituição e o egresso. Além de tentar manter também um vínculo de egressos com os outros egressos, colocando em prática o networking.

No entanto, pode-se observar com os dados obtidos, que essa integração virtual com o ex-aluno não influencia no Índice Geral de Curso da instituição. Pois, conforme tabela 4, das que possuem o IGC máximo - igual a cinco -, menos da metade, ou seja, $46 \%$ tem o contato virtual com o egresso. Já nas de IGC igual a quatro, um percentual menor ainda, 33\% têm esse contato.

TABELA 4 Informações sobre IGC

\begin{tabular}{crrrrr} 
IGC & \multicolumn{4}{c}{ Tem site relacionado ao egresso? } & TOTAL \\
\cline { 3 - 5 } 4 & 15 & $33 \%$ & 31 & $67 \%$ & 46 \\
5 & 11 & $46 \%$ & 13 & $54 \%$ & 24
\end{tabular}

Fonte: elaboração própria, 2011

Quando comparamos um IGC com o outro, percebemos que a diferença da porcentagem das instituições com IGC igual a quatro e as com igual a cinco não é tão significante. Para poder inferir sobre essa relação é necessário um estudo mais aprofundado sobre os assuntos, visando identificar se existe correlação entre essas duas variáveis. 


\section{CONSIDERAÇÕES FINAIS}

A presente pesquisa mostrou, através da revisão bibliográfica, a importância de se considerar os diversos atores sociais que demandam ações da universidade no processo de avaliação de desempenho dessas instituições, principalmente, no que concerne a integrar a visão dos egressos. Nessa perspectiva, fez-se um levantamento de dados acerca das universidades com os melhores IGCs e das formas virtuais de relação com o ex-aluno que essas universidades mantêm, procurando perceber alguma relação entre prática do contato com o egresso e o alcance de bons resultados de desempenho.

No entanto, o que se pode observar é que muitas das instituições de ensino superior não possuem um espaço virtual para manter um vinculo com o egresso e algumas das que possuem esse espaço, não o atualizam. Sendo assim, ao contrário do que a literatura especializada mostra, a opinião do egresso não tem tido grande consideração nas avaliações institucionais. Essa falta de consideração fica ainda mais evidente nas instituições que até disponibilizam um espaço virtual, mas não aproveitam esse espaço e a riqueza das informações que esse meio pode fornecer para a instituição.

Sendo assim, a partir dos resultados apresentados, conclui-se que a existência de uma página eletrônica que mantenha um vinculo com o egresso não influencia no Índice Geral de Curso. No entanto, isso não significa que a opinião do egresso não interfira no IGC, pois tais informações podem ser recolhidas de outras formas que não foram exploradas por tal artigo e que o nível da integração virtual não seja o ideal, distorcendo quaisquer relações de causa e efeito entre esses parâmetros analisados.

\section{REFERÊNCIAS}

ABREU JUNIOR, Nelson de. Sistema(s) de avaliação da educação superior brasileira. Cad. CEDES [online]. 2009, vol.29, n.78, p. 257-269. ISSN 0101-3262.

ALVES, Emilaura; ROSSI, Camila Elizandra and VASCONCELOS, Francisco de Assis Guedes de. Nutricionistas egressos da Universidade Federal de Santa Catarina: áreas de atuação, distribuição geográfica, índices de pós-graduação e de filiação aos órgãos de classe. Rev. Nutr. [online]. 2003, vol.16, n.3, p. 295-304. ISSN 1415-5273.

BROCHADO, Marina R.; PITHON, Antônio J. C.; PEREIRA, Marcelo C. QFD Instrumento de Auto Avaliação nas Instituições de Ensino Superior. In: ENCONTRO NACIONAL DE ENGENHARIA DE PRODUÇÃO, XXVI, 2006, Fortaleza. Anais do Enegep 2006.

Fortaleza: ABEPRO, 2006. 
CERQUEIRA-ADÃO. S. A. R, ANDREATA, T, SANTOS, S.I, VAZ.F.N, PERLEBERG, C.S, LOVATO, A.C.A. A avaliação de curso superior: o caso do curso superior de tecnologia em agronegócio da universidade federal do pampa - unipampa. Rev. GUAL., Florianópolis, v.4, n. 2, p.146-166, mai/ago. 2011.

CORDEIRO, Célio de Oliveira; MOTTA, Regis da Rocha. A qualidade do Ensino pela Ótica do Cliente. In: ENCONTRO NACIONAL DE ENGENHARIA DE PRODUÇÃO, XXVIII, 2008, Rio de Janeiro. Anais do Enegep 2008. Rio de Janeiro: ABEPRO, 2008.

COSTA, Ana Carolina R. da, ÂNGELO DE DEUS, Beatriz F. Análise da atuação do engenheiro de produção após conclusão do curso na Universidade Federal de Santa Catarina. In: SIMPÓSIO DE ENGENHARIA DE PRODUÇÃO, XV, 2008, São Paulo. Anais do Simpep 2008. Fortaleza: UNESP, 2008.

ESPARTEL, Lélis B. O uso da opinião dos egressos como ferramenta de avaliação de cursos: o caso de uma instituição de ensino superior catarinense. Revista Alcance - Eletrônica, v. 16, $\mathrm{n}^{\circ} 01, \mathrm{p} .103-114$. ISSN 1983-716x

LOUSADA, Ana Cristina Z.; MARTINS, Gilberto de A. Egressos como fonte e informação à gestão dos cursos de ciências contábeis. Revista de Contabilidade e Finanças - USP, São Paulo, n. 37, p. 73 - 84, Jan./Abr. 2005.

LUIZ, Natália Mattos; COSTA, Aline Franco Da and COSTA, Helder Gomes. Influência da graduação em engenharia de produção no perfil dos seus egressos: percepções discentes. Avaliação (Campinas) [online]. 2010, vol.15, n.1, p. 101-120. ISSN 1414-4077.

MEIRA, Maria Dyrce Dias and KURCGANT, Paulina. Avaliação de curso de graduação segundo egressos. Rev. esc. enferm. USP [online]. 2009, vol.43, n.2, p. 481-485. ISSN 00806234.

POLIDORI, Marlis Morosini. Políticas de avaliação da educação superior brasileira: Provão, SINAES, IDD, CPC, IGC e... outros índices. Avaliação (Campinas) [online]. 2009, vol.14, n.2, pp. 439-452. ISSN 1414-4077.

RODRIGUES,C.M.C. Aplicação do modelo de avaliação integrado ao planejamento anual na faculdade da serra gaúcha (FSG): um estudo de caso. Rev. GUAL., Florianópolis, v.4, n. 2, p.29-52, mai/ago. 2011

SOBRAL, Fernanda A. da Fonseca. Qualidade acadêmica e relevância social e econômica da educação superior. Cad. CEDES [online]. 2009, vol.29, n.78, pp. 227-241. ISSN 0101-3262. 
ANEXO I Lista das instituições com IGC entre 4 e 5

\begin{tabular}{|c|c|}
\hline IES & $\begin{array}{c}\text { NOTA } \\
\text { (IGC) }\end{array}$ \\
\hline FUNDAÇÃO UNIVERSIDADE DO ESTADO DE SANTA CATARINA & 4 \\
\hline FUNDAÇÃO UNIVERSIDADE FEDERAL DA GRANDE DOURADOS & 4 \\
\hline FUNDAÇÃO UNIVERSIDADE FEDERAL DO VALE DO SÃO FRANCISCO & 4 \\
\hline PONTIFÍCIA UNIVERSIDADE CATÓLICA DE SÃO PAULO & 4 \\
\hline PONTIFÍCIA UNIVERSIDADE CATÓLICA DO RIO DE JANEIRO & 4 \\
\hline PONTIFÍCIA UNIVERSIDADE CATÓLICA DO RIO GRANDE DO SUL & 4 \\
\hline UNIVERSIDADE DE BRASÍLIA & 4 \\
\hline UNIVERSIDADE DE SANTA CRUZ DO SUL & 4 \\
\hline UNIVERSIDADE DO ESTADO DO AMAZONAS & 4 \\
\hline UNIVERSIDADE DO ESTADO DO RIO DE JANEIRO & 4 \\
\hline UNIVERSIDADE DO VALE DO RIO DOS SINOS & 4 \\
\hline UNIVERSIDADE ESTADUAL DE LONDRINA & 4 \\
\hline UNIVERSIDADE ESTADUAL DE MARINGÁ & 4 \\
\hline UNIVERSIDADE ESTADUAL DE PONTA GROSSA & 4 \\
\hline UNIVERSIDADE ESTADUAL DO NORTE FLUMINENSE DARCY RIBEIRO & 4 \\
\hline UNIVERSIDADE ESTADUAL DO OESTE DO PARANÁ & 4 \\
\hline UNIVERSIDADE ESTADUAL DO RIO GRANDE DO SUL & 4 \\
\hline UNIVERSIDADE ESTADUAL PAULISTA JÚLIO DE MESQUITA FILHO & 4 \\
\hline UNIVERSIDADE FEDERAL DA BAHIA & 4 \\
\hline UNIVERSIDADE FEDERAL DA PARAÍBA & 4 \\
\hline UNIVERSIDADE FEDERAL DE ALFENAS & 4 \\
\hline UNIVERSIDADE FEDERAL DE CAMPINA GRANDE & 4 \\
\hline UNIVERSIDADE FEDERAL DE GOIÁS & 4 \\
\hline UNIVERSIDADE FEDERAL DE ITAJUBÁ - UNIFEI & 4 \\
\hline UNIVERSIDADE FEDERAL DE JUIZ DE FORA & 4 \\
\hline UNIVERSIDADE FEDERAL DE MATO GROSSO DO SUL & 4 \\
\hline UNIVERSIDADE FEDERAL DE OURO PRETO & 4 \\
\hline UNIVERSIDADE FEDERAL DE PELOTAS & 4 \\
\hline UNIVERSIDADE FEDERAL DE PERNAMBUCO & 4 \\
\hline UNIVERSIDADE FEDERAL DE SANTA CATARINA & 4 \\
\hline UNIVERSIDADE FEDERAL DE SANTA MARIA & 4 \\
\hline UNIVERSIDADE FEDERAL DE SÃO JOÃO DEL REI & 4 \\
\hline UNIVERSIDADE FEDERAL DE UBERLÂNDIA & 4 \\
\hline UNIVERSIDADE FEDERAL DO CEARÁ & 4 \\
\hline UNIVERSIDADE FEDERAL DO ESPÍRITO SANTO & 4 \\
\hline UNIVERSIDADE FEDERAL DO ESTADO DO RIO DE JANEIRO & 4 \\
\hline UNIVERSIDADE FEDERAL DO PARANÁ & 4 \\
\hline UNIVERSIDADE FEDERAL DO RIO GRANDE & 4 \\
\hline UNIVERSIDADE FEDERAL DO RIO GRANDE DO NORTE & 4 \\
\hline UNIVERSIDADE FEDERAL DOS VALES DO JEQUITINHONHA E MUCURI & 4 \\
\hline
\end{tabular}




\begin{tabular}{|c|c|}
\hline UNIVERSIDADE FEDERAL FLUMINENSE & 4 \\
\hline UNIVERSIDADE FEDERAL RURAL DE PERNAMBUCO & 4 \\
\hline UNIVERSIDADE FEDERAL RURAL DO RIO DE JANEIRO & 4 \\
\hline UNIVERSIDADE FEEVALE & 4 \\
\hline UNIVERSIDADE LUTERANA DO BRASIL & 4 \\
\hline UNIVERSIDADE TECNOLÓGICA FEDERAL DO PARANÁ & 4 \\
\hline ESCOLA BRASILEIRA DE ADMINISTRAÇÃO PÚBLICA E DE EMPRESAS & 5 \\
\hline ESCOLA BRASILEIRA DE ECONOMIA E FINANÇAS & 5 \\
\hline ESCOLA DE ADMINISTRAÇÃO DE EMPRESAS DE SÃO PAULO & 5 \\
\hline ESCOLA DE DIREITO DE SÃO PAULO & 5 \\
\hline ESCOLA DE ECONOMIA DE SÃO PAULO & 5 \\
\hline ESCOLA DE GOVERNO PROFESSOR PAULO NEVES DE CARVALHO & 5 \\
\hline FACULDADE DE ADMINISTRAÇÃO DE EMPRESAS & 5 \\
\hline FACULDADE DE ECONOMIA E FINANÇAS IBMEC & 5 \\
\hline FACULDADE DE MEDICINA DE SÃO JOSÉ DO RIO PRETO & 5 \\
\hline FACULDADE DE ODONTOLOGIA SÃO LEOPOLDO MANDIC & 5 \\
\hline FACULDADE FUCAPE & 5 \\
\hline FACULDADE JESUÍTA DE FILOSOFIA E TEOLOGIA & 5 \\
\hline $\begin{array}{l}\text { FUNDAÇÃO UNIVERSIDADE FEDERAL DE CIÊNCIAS DA SAÚDE DE } \\
\text { PORTO ALEGRE }\end{array}$ & 5 \\
\hline FUNDAÇÃO UNIVERSIDADE FEDERAL DE VIÇOSA & 5 \\
\hline INSPER INSTITUTO DE ENSINO E PESQUISA & 5 \\
\hline INSTITUTO MILITAR DE ENGENHARIA & 5 \\
\hline INSTITUTO TECNOLÓGICO DE AERONÁUTICA & 5 \\
\hline UNIVERSIDADE FEDERAL DE LAVRAS & 5 \\
\hline UNIVERSIDADE FEDERAL DE MINAS GERAIS & 5 \\
\hline UNIVERSIDADE FEDERAL DE SÃO CARLOS & 5 \\
\hline UNIVERSIDADE FEDERAL DE SÃO PAULO & 5 \\
\hline UNIVERSIDADE FEDERAL DO RIO DE JANEIRO & 5 \\
\hline UNIVERSIDADE FEDERAL DO RIO GRANDE DO SUL & 5 \\
\hline UNIVERSIDADE FEDERAL DO TRIÂNGULO MINEIRO & 5 \\
\hline
\end{tabular}

